\title{
DIFFERENTIAL ACTIVATION OF HUMAN SKIN CELLS BY PLATELET ACTIVATING FACTOR: STIMULATION OF PHOSPHOINOSITIDE TURNOVER AND ARACHIDONIC ACID MOBILIZATION IN KERATINOCYTES BUT NOT IN FIBROBLASTS
}

\author{
Gary J. Fisher, Harvinder S. Talwar, Neil S. Ryder ${ }^{+}$and John J. Voorhees
}

Department of Dermatology,

University of Michigan Medical Center

Ann Arbor, MI 48109

Received July 19, 1989

SUMMARY: Treatment of cultured adult human keratinocytes with platelet activating factor (PAF) resulted in a rapid, dose dependent accumulation of inositol phosphates. Inositol trisphosphate $\left(\mathrm{IP}_{8}\right)$, inositol bisphosphate $\left(\mathrm{IP}_{2}\right)$ and inositol phosphate (IP) were elevated within 15 seconds of exposure to PAF ( $1 \mu \mathrm{M})$. Lyso-PAF, phosphatidylcholine (PC) and lyso-PC had no effect on levels of inositol phosphates, indicating that the effect of PAF was specific. PAF also raised cellular 1,2-diacylglycerol content (2-fold) within two minutes of addition and stimulated mobilization of arachidonic acid (AA) and release of prostaglandin $E_{2}$. In contrast, PAF did not stimulate phosphoinositide turnover or AA release in cultured dermal fibroblasts. These results suggest that the inflammatory effects of PAF in human skin result, at least in part, from its ability to directly activate keratinocytes and stimulate release of pro-inflammatory eicosanoids.

- 1989 Academic Press, Inc.

Platelet activating factor (PAF) is derived from 1-0-alkyl, 2-acyl phosphatidylcholine and is a potent mediator of platelet aggregation, bronchial constriction and inflammation. PAF is synthesized primarily by polymorphonuclear neutrophils, monocytes, platelets, macrophages and endothelial cells (for review see 1-3).

PAF exerts its effects on target cells through specific receptors coupled to phosphoinositide-specific phospholipase C (PLC). This reaction results in the formation of two intracellular second messengers, inositol 1,4,5-trisphosphate $\left(\mathrm{IP}_{3}\right)$ and 1,2-diacylglycerol (DAG). $\mathrm{IP}_{3}$ acts to raise intracellular calcium and DAG stimulates protein kinase $\mathrm{C}(\mathrm{PK}-\mathrm{C})$. Elevated intracellular calcium and activated PK-C act synergistically to initiate a cascade of biochemical reactions that modulate cell function (for review see 4,5).

Intradermal injection of PAF into human subjects elicits an inflammatory reaction in the skin characterized by erythemia and a perivascular mixed cellular infiltrate (6). Mallet et al. have reported increased levels of PAF in the skin of patients with psoriasis and have suggested that

- To whom correspondence and reprint requests should be addressed.

+ Present Address: Sandoz Forchungsinstitut, Brunner Strasse, 59, A-1235 Vienna, Austria.

Abbreviations: AA, arachidonic acid; BK, bradykinin; DAG, 1,2-diacylglycerol; IP, inositol phosphate; $\mathbb{I P}_{2}$, inositol bisphosphate; $\mathrm{IP}_{3}$, inositol trisphosphate; PAF, platelet activating factor; $\mathrm{PGE}_{2}$, prostglandin $\mathrm{E}_{2}$; PK-C, protein kinase $\mathrm{C}$; PLC, phospholipase C; TPA, 12-0tetradecanoylphorbol-13-acetate. 
PAF may be involved in the pathogenesis of this hyperplastic inflammatory skin disease (7). Keratinocytes are the predominant cell type in the epidermis and are capable of responding to, and synthesizing a variety of pro-proliferative and pro-inflammatory cytokines (interleukin-1, interleukin-6, transforming growth factor- $\alpha$, tumor necrosis factor and granulocyte/monocyte colony stimulating factor) and eicosanoids $\left(\mathrm{PGE}_{2}, \mathrm{PGF}_{2}\right.$ and 12-HETE) (8-13). Treatment of keratinocytes in vitro and skin in vivo with the PK-C activator 12-0-tetradecanoylphorbol-13acetate (TPA) induces many of these mediators (10-12), suggesting that their levels may be regulated in some manner by PK-C. This concept is further supported by the demonstration that the psoriasis-like inflammatory reaction of mouse skin to TPA is blocked by the PK-C inhibitor sphingosine (14). The ability of PAF to induce cutaneous inflammation thus raises the possibility that it may act to induce the release pro-inflammatory mediators from epidermal keratinocytes via direct activation of the PLC/PK-C signal transduction system. Alternatively, PAF may directly activate mediator release from fibroblasts within the dermis which then in turn may act on keratinocytes. To investigate this issue we have examined the ability of PAF to induce phosphoinositide turnover and arachidonic acid mobilization in cultured adult human keratinocytes and dermal fibroblasts.

\section{MATERIALS AND METHODS}

Materials. $\quad\left[\gamma^{32} \mathrm{P}\right] \mathrm{ATP},\left[{ }^{3} \mathrm{H}\right]$ arachidonic acid, $\left[{ }^{3} \mathrm{H}\right] \mathrm{myo}-$ inositol and prostaglandin $\mathrm{E}_{2}$ radioimmunoassay assay kit were obtained from New England Nuclear (Boston, MA). Pertussis toxin was purchased from List Biochemicals (Campbell, CA). Platelet activating factor was obtained from Serdary Biochemicals, (London, Canada). Lyso-platelet activating factor, phosphatidylcholine, phosphatidylserine and lyso-phosphatidylcholine were from Avanti Polar Lipids (Birmingham, AL). Dowex IX-8 formate form was from BioRad Laboratories (Richmond, CA). Modified MCDB 153 keratinocyte growth media (KGM) and growth factor free keratinocyte basal media (KBM) were obtained from Clonetics, Inc. (San Diego, CA).

Cell Culture. Keratome biopsies $(0.2 \mathrm{~mm}$ depth) of human epidermis were obtained from adult volunteers. Epidermal cells were disaggregated by incubation at $37^{\circ}$ for 30 minutes in $0.25 \%$ trypsin, $0.1 \%$ EDTA. Cells were plated at $10^{7}$ cells/T-75 flask in KGM (15). Cells were expanded by passage at $80 \%$ confluency and utilized between passage 2 and 6 . Dermal fibroblasts were grown from dermal explants in McCoy's 5A media containing $10 \%$ fetal calf serum.

Labelling of cells and measurement of $\left[{ }^{3} \mathrm{H}\right]$ inositol phosphates. Keratinocytes and fibroblasts were seeded in $35 \mathrm{~mm}$ dishes and allowed to grow to $70 \%$ confluency. Keratinocytes were labelled with $\left[{ }^{3} \mathrm{H}\right] \mathrm{myo}$-inositol $(1 \mu \mathrm{Ci} / \mathrm{ml})$ in inositol free $\mathrm{KBM}$ for 48 hours. Fibroblasts were labelled similarly in Medium 199. The media was removed and cells were incubated in phosphate buffered saline containing $10 \mathrm{mM} \mathrm{LiCl}$ for 10 minutes prior to addition of agonist. Following stimulation, ice cold methanol/HCL (1:0.01) was added and the cells scraped from the dish. $\left[{ }^{3} \mathrm{H}\right]$ inositol phosphates were separated by Dowex ion exchange chromatography and quantified by liquid scintillation counting (16).

Measurement of 1,2-diacylglycerol. Cellular 1,2-diacylglycerol content was determined by the method of Preiss et al., utilizing E. Coli diacylglycerol kinase (17).

Measurement of arachidonic acid release and prostaglandin $E_{2}$. Keratinocytes and fibroblasts (80\% confluent in $35 \mathrm{~mm}$ dishes) were labelled with $\left.{ }^{3} \mathrm{H}\right]$ arachidonic acid $(0.5 \mu \mathrm{Ci} / \mathrm{ml})$ for 16 hours in KBM and Delbecco's modified Eagles medium with $0.2 \%$ fetal calf serum, respectively. The cells were washed to remove unincorporated radioactivity and placed in $1 \mathrm{ml}$ of media. At the indicated times following addition of agonist, $0.5 \mathrm{ml}$ of media was removed, acidified and extracted with an equal volume of ethylacetate. The ethylacetate extracts were dried in scintillation vials and counted. For measurement of prostaglandin $E_{2}$, keratinocytes were grown in KGM con- 
taining $1 \mu \mathrm{M}$ unlabelled arachidonic acid for 24 hours. Cells were washed with KBM to remove unincorporated arachidonic acid prior to stimulation with agonist for the indicated times. Prostaglandin $E_{2}$ in the media was determined using a commercial radioimmunoassay kit.

RESULTS AND DISCUSSION: Exposure of cultured adult human keratinocytes to PAF $(1 \mu \mathrm{M})$ resulted in rapid significant elevations in $\mathrm{IP}_{3}, \mathrm{IP}_{2}$ and $\mathrm{IP}$ (figure 1 ). $\mathrm{IP}_{3}$ was maximally elevated (8-fold) within 15 seconds and remained above the initial level for at least 4 minutes. $I_{2}$ increased over 1 minute and remained maximally elevated (8-fold) for at least 4 minutes. IP increased steadily between 0 and 4 minutes to a level 10 -fold above the initial value. Increased formation of inositol phosphates was detected at PAF concentrations between $10^{-10}-10^{-5} \mathrm{M}$ (data not shown). Half maximal stimulation ocurred at $5 \times 10^{-7} \mathrm{M} \mathrm{PAF}$.

The effect of several different phospholipids on accumulation of inositol phosphates was examined. Phosphatidylcholine, Iyso-phosphatidylcholine and phosphatidylserine at $10^{-5} \mathrm{M}$ and lyso-PAF at $10^{-6} \mathrm{M}$ were unable to simulate formation of inositol phosphates in human keratinocytes (data not shown). These data indicate that the ability of PAF to induce formation of inositol phosphates is specific.

In a variety of cell types, agonist-induced phosphoinositide hydrolysis is inhibited by TPA and in some cases by pertussis toxin. Evidence indicates that these agents act to uncouple agonist receptors from phospholipase $C$ by inhibition of an as yet unidentified GTP-binding protein(s) $\left(G_{x}\right)$. Inhibition by TPA is believed to occur via protein kinase $C$-mediated uncoupling of $G_{x}$ from phospholipase $C$, while inhibition by pertussis toxin may occur via ADPribosylation of $G_{x}$ thereby uncoupling it from agonist receptors (18). In cultured adult human keratinocytes TPA caused significant inhibition of PAF-induced formation of inositol phosphates (figure 2). IP, $\mathrm{IP}_{2}$, and $\mathrm{IP}_{3}$ were each inhibited $50 \%$ by TPA. Treatment with pertussis toxin also resulted in inhibition of PAF-induced formation of inositol phosphates although to a lesser degree (25\%) than TPA (data not shown). Pertussis toxin has been reported to inhibit PAFinduced phosphoinositide turnover in neutrophils (19) and macrophages (20) but not to be inhibitory in monocytic leukemic U-937 cells (21). Taken together the phospholipid specificity and sensitivity to TPA and pertussis toxin of PAF-induced formation of inositol phosphates are con-

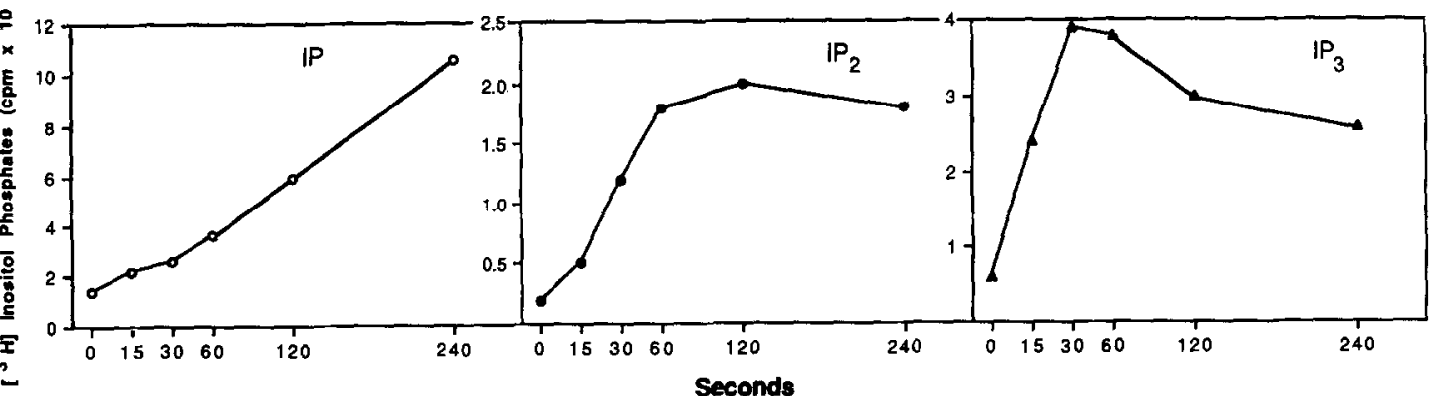

Figure 1. Time course of PAF-induced formation of inositol phosphates in cultured adult human keratinocytes. Keratinocytes were labelled with [ $\left.{ }^{2} \mathrm{H}\right]$ myo-inositol $(1 \mu \mathrm{Ci} / \mathrm{ml})$ for 48 hours in inositol free KBM. [ ['H]inositol phosphates were extracted and analyzed by Dowex chromatography as described in "METHODS". Data points are means \pm SEM for triplicate dishes from three separate experiments. PAF concentration $1 \mu \mathrm{M}$. 

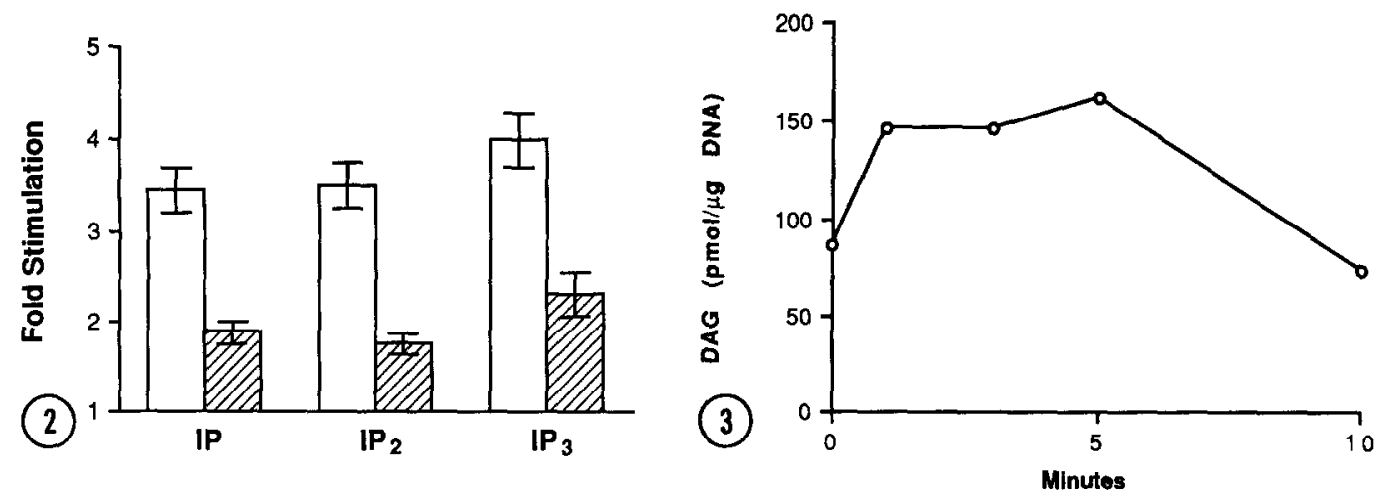

Figure 2. Inhibition of PAF-induced formation of inositol phosphates by TPA. Experimental conditions were similar to those described in the legend to figure 1 with the exception that the keratinocytes were incubated with TPA $(50 \mathrm{nM})$ for 20 minutes prior to the addition of PAF $(2 \mu \mathrm{M})$ for four minutes. $\square$, PAF; $\square$, TPA + PAF. Results are the means \pm SEM of triplicate dishes from two separate experiments.

Figure 3. Time course of PAF-induced formation of 1,2-diacylglycerol (DAG) in cultured human keratinocytes. Keratinocytes $\left(4.5 \times 10^{6} / 100 \mathrm{~mm}\right.$ dish) were treated with PAF $(1 \mu \mathrm{M})$ for the indicated times. At the termination of the incubation, media was aspirated and the cells were scraped from the dish in ice cold methanol. DAG was extracted and quantified as described in "METHODS". Data points are the means of triplicate dishes from a representative experiment. The experiment was repeated three times with similar results.

sistent with PAF acting through specific receptors expressed on human keratinocytes coupled via a G-protein to phospholipase C.

In addition to producing $\mathrm{IP}_{3}$, agonist-induced phosphoinositide turnover is associated with the production of a second intracellular messenger DAG. We therefore investigated the effects of PAF on DAG content in cultured keratinocytes. Addition of PAF caused a rapid transient increase in DAG content (figure 3). DAG was maximally stimulated (2-fold) within 1 minute and remained elevated for 5 minutes, after which it returned to the initial level. The slower kinetics of PAF-induced DAG formation compared to that of $\mathrm{IP}_{3}$ (figure 1) suggest that phospholipid headgroup classes other than phosphoinositides may serve as sources for at least some portion of the elevated DAG, as has been observed in PAF-stimulated peritoneal macrophages (22).

In addition to stimulating phosphoinositide turnover and DAG formation in human keratinocytes, PAF also elicited mobilization of arachidonic acid and prostaglandin $\mathrm{E}_{2}$ synthesis. PAF-stimulated release of radioactivity from keratinocytes labelled with $\left[{ }^{3} \mathrm{H}\right]$ arachidonic acid was dose and time dependent. Arachidonic acid release was elevated within 5 minutes and continued to increase over 30 minutes (figure 4A). Release of radioactivity from [ ${ }^{3} \mathrm{H}$ ]arachidonic acid labelled keratinocytes was elevated 3-fold and prostaglandin $E_{2}$ release was elevated 5-fold following exposure of keratinocytes to PAF for 15 minutes (figure 4B).

A recent report indicates that human dermal fibroblasts are capable of synthesizing PAF (23). Since cells that synthesize PAF of ten also respond to it, dermal fibroblasts, in addition to keratinocytes, may be targets for the actions of PAF in skin. To investigate this, we determined whether PAF was able to stimulate phosphoinositide turnover and/or arachidonic acid mobilization in cultured adult human dermal fibroblasts. PAF caused no detectable increases in IP, $\mathrm{IP}_{2}, \mathrm{IP}_{3}$ or release of $\left[^{3} \mathrm{H}\right]$ arachidonic acid metabolites. In contrast, bradykinin (BK), a known 

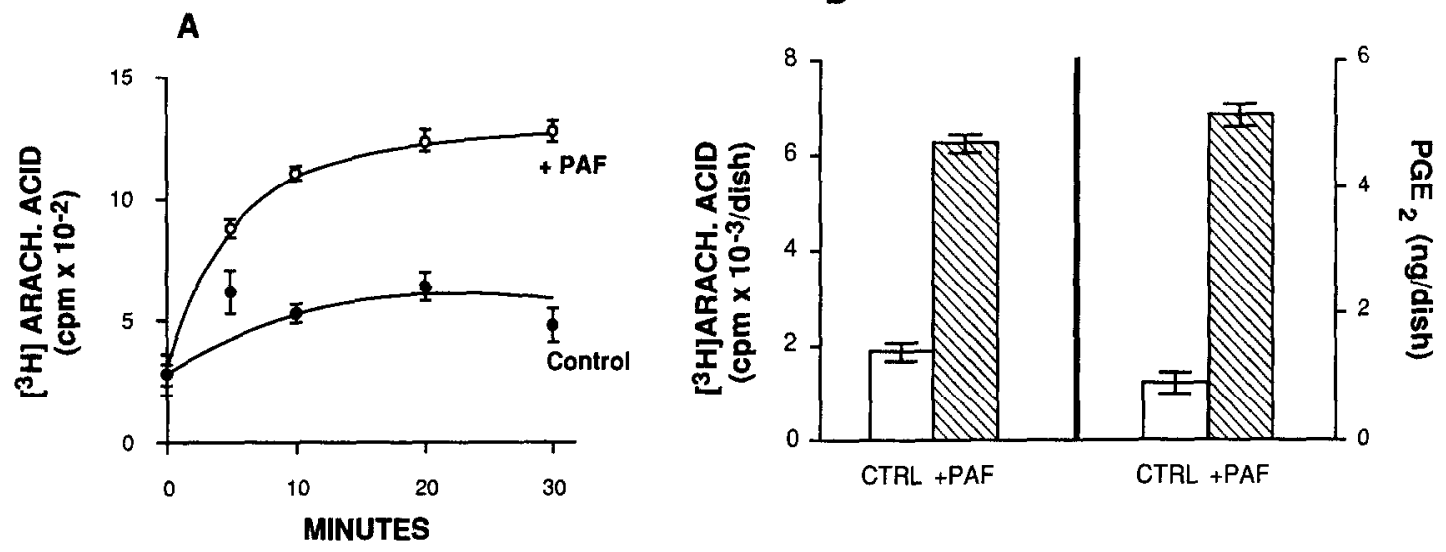

Figure 4. PAF-stimulated release of arachidonic acid and prostaglandin $E_{2}$ in cultured human keratinocytes. A) Keratinocytes were labelled with $\left[{ }^{3} \mathrm{H}\right]$ arachidonic acid $(0.5 \mu \mathrm{Ci} / \mathrm{ml})$ for 16 hours. Cells were stimulated with PAF $(1 \mu \mathrm{M})$ for the indicated times and the radioactivity in the media was extracted and counted as described in "METHODS". B) Keratinocytes were grown in KGM supplemented with arachidonic acid $(1 \mu \mathrm{M})$ for 24 hours. Left panel: Experimental conditions similar to those in (A). Keratinocytes were treated with PAF $(1 \mu \mathrm{M})$ for 15 minutes. Right panel: Unlabelled cells were stimulated with PAF $(1 \mu \mathrm{M})$ for 15 minutes. Prostaglandin $\mathrm{E}_{2}$ was quantified by RIA. Results are the means \pm SEM for triplicate dishes from three separate experiments.

phospholipase $C$ agonist in fibroblasts (24) significantly elevated inositol phosphates and release of arachidonic acid (Table I). The lack of responsiveness of cultured human dermal fibroblasts to PAF suggests that these cells may not express PAF receptors.

The above data demonstrate that adult human keratinocytes, but not dermal fibroblasts, are direct targets for the actions of PAF. PAF activates both arms of the bifurcating PLC/PK-C signal transduction system in human keratinocytes, stimulating $\mathrm{IP}_{3}$ and $\mathrm{DAG}$ formation. In addition, PAF induces eicosanoid release. The activation of keratinocytes by PAF is likely to be an important mechanism through which PAF exerts its inflammatory effects in skin. Infiltration of polymorphonuclear leukocytes and macrophages, which synthesize PAF, is commonly observed in

TABLE I

Bradykinin but not PAF Stimulates Phosphoinositide Turnover and Arachidonic Acid Release in Human Dermal Fibroblasts

\begin{tabular}{lrrrrr}
\hline & \multicolumn{2}{c}{ ['H]Inositol Phosphates (cpm)* } & \\
\cline { 2 - 5 } Addition & IP & \multicolumn{1}{c}{ IP $_{2}$} & IP $_{3}$ & AA Metabolites (cpm)** \\
\hline None & & $5,713 \pm 243$ & $529 \pm 29$ & $2,674 \pm 211$ & $3940 \pm 367$ \\
PAF & $10^{-7}$ & $5,425 \pm 290$ & $466 \pm 16$ & $1,957 \pm 79$ & $2782 \pm 290$ \\
& $10^{-6} \mathrm{M}$ & $5,103 \pm 332$ & $475 \pm 33$ & $2,512 \pm 123$ & $3379 \pm 568$ \\
& $10^{-6} \mathrm{M}$ & $5,441 \pm 280$ & $448 \pm 27$ & $1,852 \pm 45$ & $3193 \pm 478$ \\
BK & $1 \mu \mathrm{M}$ & $47,510 \pm 792$ & $3,910 \pm 227$ & $6,446 \pm 405$ & $7913 \pm 235$ \\
\hline
\end{tabular}

Inositol phosphates (IP, $\mathbf{I P}_{2}$ and $\mathbf{I P}_{\mathbf{3}}$ ) and arachidonic acid $(A A)$ measured four and 30 minutes after addition of agonist, rêrpectively. BK, bradykinin; PAF, platelet activating factor.

* Values are means \pm SEM of quadruplicate dishes from a representative experiment repeated three times.

*Values are means $\pm S E M$ of triplicate dishes from a representative experiment repeated twice. 
a variety of inflammatory skin diseases. Our data suggest that the presence of PAF within the epidermis would lead to stimulation of protein kinase $C$ and calcium/calmodulin regulated enzymes within keratinocytes, resulting in elevated release of pro-inflammatory eicosanoids. PAF may also influence many other keratinocyte protein kinase $\mathrm{C}$-mediated responses such as cytokine release, growth and differentiation.

We have previously demonstrated that inflammatory factors such as bradykinin, thrombin and histamine also stimulate phospholipase C-catalyzed phosphoinositide turnover and elevate DAG content in human keratinocytes (25). We therefore propose that the phospholipase $\mathrm{C}$ /protein kinase $\mathrm{C}$ signal transduction system in human keratinocytes is a key pathway through which mediators of skin inflammation act. This hypothesis predicts that receptor antagonists of PAF, bradykinin, histamine, and thrombin and inhibitors of phospholipase $C$ and protein kinase $\mathrm{C}$ might be effective anti-inflammatory agents in skin. Investigations are in progress to address this issue.

\section{ACKNOWLEDGMENTS}

This work was supported by National Public Health Services Grant AR39691 (GJF), the National Psoriasis Foundation (HST), Sandoz Forschungsinstitut (NSR) and the Babcock fund for Dermatological Research. The authors thank Ms. Claudia Hagedon for expert secretarial assistance in the preparation of this manuscript.

\section{REFERENCES}

1. Hanahan, D.J. (1986) Ann. Rev. Biochem. 55, 483-509.

2. Benveniste, J. (1985) Adv. Prost. Throm. Leuk. Res. 13, 11-18.

3. Whatley, R.E., Zimmerman, G.A., McIntyre, T.M., Taylor, R., and Prescott, S.M. (1987) Seminars in Thrombosis and Hemostasis. 13, 445-453.

4. Berridge, M.J. (1987) Annu. Rev. Biochem. 56, 159-193.

5. Majerus, P.W. (1986-1987) Harvey. Lect. 82, 145-155.

6. Archer, C.B., Page, C.P., Morley, J., and MacDonald, D.M. (1985) Br. J. Dermatol. 112, 285-290.

7. Mallet, A.I., Cunningham, F.M., Wong, E., and Greaves, M.W. (1987) 17B, 640-642.

8. Luger, T.A., Sztein, M.B., Schmidt, J.A., Murphy, P., Grabner, G., and Oppenheim, J.J. (1983) Fed. Proc. 42, 2772-2776.

9. Kirnbauer, R., Kock, A., Schwarz, T., Urbanski, A., Krutmann, J., Borth, W., Damm, D., Shipley, G., Ansel, J.C., and Luger, T.A. (1989) Am. J. Dermatopathol. 11, 69-73.

10. Pittelkow, M.R., Lindquist, P.B., Abraham, R.T., Graves-Deal, R., Derynck, R., and Coffey, R.J. (1989) J. Biol. Chem. 264, 5164-5171.

11. Chodakewitz, J.A., Kupper, T.S., and Coleman, D.L. (1988) J. Immunol. 140, 832-836.

12. Kupper, T.S. (1989) Am. J. Dermatopathol. 11, 69-73.

13. Galey, C.I., Ziboh, V.A., Marcelo, C.L., and Voorhees, J.J. (1985) J. Invest. Dermatol. 85, 319-323.

14. Gupta, A.K., Fisher, G.J., Elder, J.T., Nickoloff, B.J., and Voorhees, J.J. (1988) J. Invest. Dermatol. 91, 486-491.

15. Boyce, S.T., and Ham, R.G. (1983) J. Invest. Dermatol. 81, 33-40.

16. Berridge, M.J., Dawson, R.M., Downes, C.P., Heslop, J.P., and Irvine, R.F. (1983) Biochem. J. 212, 473-482.

17. Preiss, J., Loomis, C.R., Bishop, W.R., Stein, R., Niedel, J.E., and Bell, R.M. (1986) J. Biol. Chem. 261, 8597-8600.

18. Smith, C. D., Uhing, R.J., and Snyderman, R. (1987) J. Biol. Chem. 262, 6121-6127.

19. Verghese, M.W., Charles, L., Jakoi, L., Dillon, S.B., and Snyderman, R. (1987) J. Immunol. 138, 4374-4380. 
20. Huang, S.J., Monk, P.N., Downes C.P., and Whetton, A.D. (1988) Biochem. J. 249, 839845.

21. Barzaghi, G., Sarau, H.M., and Mong, S. (1988) J. Pharm. Exper. Ther. 248, 559-566.

22. Uhing, R.J., Prpie, V., Hollenbach, P.W., and Adams, D.O. (1989) J. Biol. Chem. 264, 9224-9230.

23. Michel, L., Denizot, Y., Thomas, Y., Jean-Louis, F., Pitton, C., Benveniste, J., and Dubertret, L. (1988) J. Immunol. 141, 948-953.

24. Vicentini, L.M., and Villereal, M.L. (1984) Biochem. Biophys. Res. Comm. 123, 663-670.

25. Talwar, H.S., Fisher, G.J., Harris, V.A., and Voorhees, J.J. (1989) J. Invest. Dermatol. (In press). 